\section{Commentary: Functional tricuspid regurgitation: Finally, a ventricular solution to a ventricular problem}

\author{
Nicolas H. Pope, MD, and Gorav Ailawadi, MD, MBA
}

Functional tricuspid regurgitation (TR) represents a challenging but common clinical scenario. Concomitant right ventricular (RV) dysfunction is the major reason for poor medical and surgical outcomes in patients with TR. Nevertheless, tricuspid repair in carefully selected patients has become the dominant approach by surgeons. Although a wide variety of repair techniques have been described, the mainstay includes reduction of the annular diameter in an effort to address RV function. Notable, the geometry of the $\mathrm{RV}$ is more complex, more variable, and more difficult to reliably image than the left ventricle. ${ }^{1}$ In this report, Takeshita and colleagues ${ }^{2}$ present 2 subvalvular techniques to address chordal tethering and functional TR with papillary repositioning and annular repositioning, highlighting the importance of ventricular components contributing to this disease.

To better understand these subvalvular approaches to address TR, some insights into subvalvular procedures for functional mitral regurgitation should be noted. Our group first reported papillary muscle relocation to aid in repair for ischemic mitral valve repair. ${ }^{3}$ The major difference compared with that described here is the requirement of a chronically scarred posterolateral papillary muscle from ischemic mitral regurgitation (MR). Nevertheless, this technique is not always reproducible, as the there are times that the annulus becomes tethered as this suture is tied down if

From the Division of Cardiothoracic Surgery, Department of Surgery, University of Virginia, Charlottesville, Va.

Disclosures: Dr Ailawadi reported consultant to Edwards, Medtronic, Abbott, and Gore, Admedus. Dr Pope reported no conflicts of interest.

The Journal policy requires editors and reviewers to disclose conflicts of interest and to decline handling or reviewing manuscripts for which they may have a conflict of interest. The editors and reviewers of this article have no conflicts of interest.

Received for publication May 30, 2020; revisions received May 30, 2020; accepted for publication June 6, 2020; available ahead of print June 14, 2020.

Address for reprints: Gorav Ailawadi, MD, MBA, Division of Cardiothoracic Surgery, Department of Surgery, University of Virginia, P.O. Box 800679, Charlottesville, VA 22908 (E-mail: GA3F@virginia.edu).

JTCVS Techniques 2020;3:166-7

2666-2507

Copyright (c) 2020 The Authors. Published by Elsevier Inc. on behalf of The American Association for Thoracic Surgery. This is an open access article under the CC BY-NCND license (http://creativecommons.org/licenses/by-nc-nd/4.0/).

https://doi.org/10.1016/j.xjtc.2020.06.006

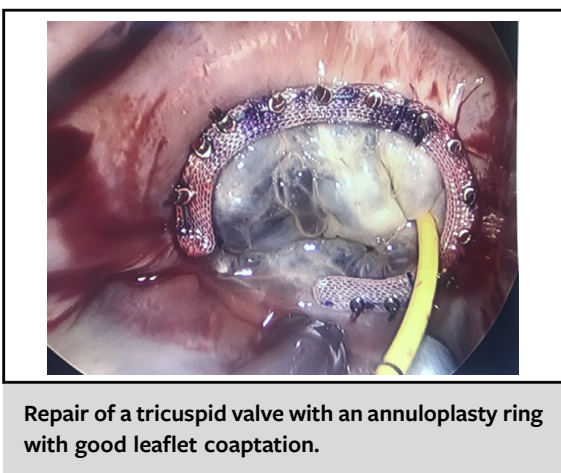

CENTRAL MESSAGE

Failure of annuloplasty alone for

functional TR suggest that at-

tempts at subvavular techniques

to address the mechanisms of

failure be made.

the inferolateral wall is akinetic. Moreover, the RV endocardium is much more fragile in this regard, as evidenced by difficulty in the development of RV endocardial fixation devices such as the FORMA (Edwards Lifesciences, Irvine, Calif) spacer.

The second challenge is the accurate measurement of the degree of tethering and the even greater difficulty in achieving adequate reduction. The analogous artificial (polytetrafluoroethylene) chordal repair for degenerative MR is critiqued by the difficulty in measuring appropriate chordal length and requires advanced knowledge and skill in both positioning on the papillary muscle as well as in the fine adjustment in chordal height. ${ }^{4,5}$ Correcting the degree of papillary tethering on a decompressed heart during functional MR can prove challenging, as inadequate tension insufficiently repositions the papillary muscle, whereas too-tight tension results in accentuation of tethering. This is made even more challenging when dealing with the RV, which tends not to dilate uniformly and in a trileaflet valve, where coaptation is more complex.

Finally, it should be noted that outcomes in tricuspid repair have historically proven challenging, with 5-year failure rates of $25 \%$ to $40 \%$ with flexible or suture annuloplasty. ${ }^{6}$ Even annuloplasty with a semi-rigid ring has reported failure rates ( 3 or $4+$ TR) of $15 \%$ to $20 \%$ at 1 month, indicating that better techniques are still needed. The advent of techniques that address the subvalvular pathology of functional TR is needed but must also be 
reproducible and easier for surgeons to perform on a decompressed heart. This leap is one of the hurdles that surgeons have to overcome compared with transcatheter approaches, which are performed in a more physiologic state. Lastly, the greatest challenge that still remains is the limited imaging and understanding of the RV/tricuspid valve complex that will need to improve if subvalvular procedures are to be performed successfully.

\section{References}

1. Hahn RT, Thomas JD, Khalique OK, Cavalcante JL, Praz F, Zoghbi WA. Imaging assessment of tricuspid regurgitation severity. JACC Cardiovasc Imaging. 2019; $12: 469-90$.
2. Takeshita M, Hirokuni A, Nagaoka E, Mizuno T. Pappilary muscle relocation and annular repositioning for functional tricuspid regurgitation. $J$ Thorac Cardiovasc Surg Tech. 2020;3:162-5.

3. Kron IL, Green GR, Cope JT. Surgical relocation of the posterior papillary muscle in chronic ischemic mitral regurgitation. Ann Thorac Surg. 2002;74:600-1.

4. Alameddine AK, DiBiasio-White E, Binnall B, Conlin F. Adjusting the neochords height for better leaflets coaptation following mitral valve repair. J Card Surg. 2019;34:610-3.

5. Rodriguez-Roda J, Miguelena J, Lopez J, Martin M, Munoz R. How to adjust neochordae length accurately in degenerative mitral regurgitation. Ann Thorac Surg. 2018;105:e183-4.

6. Navia JL, Nowicki ER, Blackstone EH, Brozzi NA, Nento DE, Atik FA, et al. Surgical management of secondary tricuspid valve regurgitation: annulus, commissure, or leaflet procedure? J Thorac Cardiovasc Surg. 2010;139:1473-82.e5.

7. McCarthy PM, Bhudia SK, Rajeswaran J, Hoercher KJ, Lytle BW, Cosgrove DM, et al. Tricuspid valve repair: durability and risk factors for failure. J Thorac Car diovasc Surg. 2004;127:674-85. 